\title{
Surrogate markers for survival in patients with AIDS and AIDS related complex treated with zidovudine
}

\author{
Mark A Jacobson, Peter Bacchetti, Antonia Kolokathis, Richard E Chaisson, Susan Szabo, \\ Bruce Polsky, Gregory T Valainis, Donna Mildvan, Donald Abrams, Judith Wilber, Edward Winger, \\ Henry S Sacks, Carol Hendricksen, Andrew Moss
}

Department of Medicine, University of California, San Francisco, and the Medical Service, San Francisco General Hospital, San Francisco, California 94110, United States

Mark A Jacobson, MD, assistant professor

Donald Abrams, MD, associate professor of clinical medicine

\section{Department of}

Epidemiology and

Biostatistics, University of

California, San Francisco, California

Peter Bacchetti, PHD, assistant adjunct professor

Andrew Moss, PHD, associate adjunct professor

Department of Medicine, Beth Israel Medical Center, New York

Antonia Kolokathis, MD, assistant attending

Department of Medicine, John Hopkins University, Baltimore, Maryland Richard E Chaisson, MD, assistant professor Carol Hendricksen, RN, clinical research nurse

Department of Medicine, Mount Sinai Hospital, New York

Susan Szabo, MD, instructor

Infectious Disease Service, Memorial Sloan Kettering Cancer Center and Cornell University Medical College, New York Bruce Polsky, MD, clinical assistant physician

Department of Medicine Tulane University Medical Center, New Orleans, Los Angeles

Gregory $\mathrm{T}$ Valainis, $\mathrm{MD}$, assistant professor

continued overleaf

$B M \mathcal{1}$ 1991:302:73-8

\begin{abstract}
Objective-To determine whether early effects of zidovudine treatment on CD4+lymphocyte count and concentrations of $\beta_{2}$ microglobulin, neopterin, or HIV p24 antigen or antibody are correlated with survival in patients with AIDS or AIDS related complex.
\end{abstract}

Design-Retrospective study of changes in laboratory markers and survival.

Setting-Multicentre trial at university hospital clinics.

Subjects -90 Patients with AIDS or AIDS related complex.

Intervention-Patients started zidovudine $200 \mathrm{mg}$ orally every four hours. Fifty six of the patients died a median 17 months after starting zidovudine; the remaining 34 patients were followed up for a median 25.5 months.

Main outcome measures-Changes in CD4+ lymphocyte count and serum concentrations of p24 antigen and antibody, $\beta_{2}$ microglobulin, and neopterin; survival of the patient.

Results-The pretreatment characteristics that independently predicted poor survival were determined using a multivariate proportional hazards model: a diagnosis of AIDS ( $v$ AIDS related complex), age over 45 years, and the logarithm of serum neopterin concentration. When these baseline characteristics were controlled for the logarithm of CD4+lymphocyte count at weeks 8-12 of treatment $(p=0.007)$ and an increase in serum $\beta_{2}$ microglobulin concentration at weeks $8-12(p=0.05)$ also independently correlated with survival. In the 38 patients with a better pretreatment prognosis, 24 month survival estimated by the product-limit method was $88 \%$ for those with a good response on both surrogate markers during early treatment compared with only $50 \%$ for those with a poor response on either marker. In the 38 with a worse pretreatment prognosis, 24 month survival was estimated to be $49 \%$ for those with a good response on both surrogate markers compared with only $18 \%$ for those with a poor response on either.

Conclusion-These data suggest that CD4+ lymphocyte count at 8-12 weeks and, perhaps, change in serum $\beta_{2}$ microglobulin concentration could be surrogate end points for clinical outcome in trials of antiretroviral drugs for patients with HIV disease.

\section{Introduction}

Treatment of symptomatic HIV infection with zidovudine or other nucleoside analogues has been the standard practice since $1986 .{ }^{12}$ Although several placebo controlled trials have shown the clinical efficacy of zidovudine in patients with AIDS and AIDS related complex (improved survival and fewer opportunistic infections), ${ }^{34}$ clearly such treatment does not result in improved long term survival for all patients. ${ }^{5}$ To date, changes in clinical or laboratory markers during treatment which would predict long term survival ("surrogate markers") have not been defined.

Zidovudine treatment improves several direct and indirect viral and immunological measures of retroviral activity (P Crocchiolo et al, 4 th international conference on AIDS, Stockholm 1988), ${ }^{36-8}$ but these effects have not been correlated with final clinical outcome. For example, zidovudine increases absolute CD4+ lymphocyte count during the first 8-12 weeks of treatment and improves survival at 24 weeks, ${ }^{3}$ but it is not known if those with improved CD4+lymphocyte counts are the long term survivors. A correlation betwen an early effect of nucleoside analogue treatment on viral or immunological markers and long term clinical outcome would be useful both for the treating clinicians and for research workers seeking early indication of clinical benefit from new antiretroviral drugs.

We studied 90 patients with AIDS and AIDS related complex who were followed up for a median two years or until death after starting zidovudine treatment. We analysed baseline clinical and laboratory characteristics predicting long term survival at the start of treatment. We then examined the early effects of zidovudine treatment on five viral and immunological markers of early HIV activity (8-12 weeks). After controlling for the effect of baseline characteristics we investigated the relation between the effect of zidovudine treatment on these markers and long term clinical outcome to see if they were correlated and so determine if any were surrogate measures of clinically important antiretroviral effect among patients surviving more than 12 weeks.

\section{Methods}

PATIENTS

Patients with a history of Pneumocystis carinit pneumonia or with symptomatic HIV disease and a CD4+lymphocyte count of $<0.2 \times 10^{9} / 1$ who had not previously received zidovudine were selected for the study. They were entered in one of two open label studies of zidovudine treatment (National Institute of Allergy and Infectious Diseases AIDS clinical trials group protocol 020 or Burroughs Wellcome treatment investigational new drug programme) between November 1986 and October 1987 and were eligible for inclusion $(a)$ if stored sera were available both from before zidovudine was started and after the initial 8-12 weeks of treatment and $(b)$ if follow up clinical information could be obtained for at least 10 months or until death. Patients were followed up until December 
Division of Infectious Diseases, Beth Israel Medical Center, New York

Donna Mildvan, MD chief

Viral and Rickettsial Disease Laboratory, California Department of Health Services, Berkeley, California

Judith Wilber, PHD, staff scientist

\section{Immunodiagnostic}

Laboratories Incorporated, San Leandro, California

Edward Winger, MD, director

Departments of Medicine and Biomathematics,

Mount Sinai School of Medicine, New York

Henry S Sacks, MD, associate professor

Correspondence to: Dr Jacobson.
1989. Zidovudine treatment was started at a dose of $200 \mathrm{mg}$ orally every four hours

\section{SURROGATE MARKER ASSAYS}

CD4+lymphocytes in peripheral blood were counted at serum collection by standard flow cytometry techniques.

Serum HIV p24 antigen concentration was measured by solid phase enzyme linked immunosorbent assay (ELISA) using an HTLV-III assay (Abbott Laboratories, Abbott Park, Illinois), which measures HIV antigen, predominantly p24. ${ }^{79}$ All pairs of samples from the same patient were batch tested in the same assay. Undiluted samples with concentrations that fell below the range of the standard curve were regarded as negative and were assigned a value that was half the difference between the cut off concentration (35-75 ng/l) and zero.

Serum $\beta_{2}$ microglobulin concentration was measured by a quantitative competitive ELISA (Pharmacia, Piscataway, New Jersey) in which serum $\beta_{2}$ microglobulin competes with enzyme labelled $\beta_{2}$ microglobulin for binding sites of antibody to $\beta_{2}$ microglobulin bound to Sepharose beads (Pharmacia). ${ }^{7}$ Normal serum $\beta_{2}$ microglobulin concentrations for homosexual men are $\leqslant 254 \mathrm{nmol} / \mathrm{l}(3.0 \mathrm{mg} / \mathrm{l})$.

Serum neopterin concentration was measured by a competitive radioimmunoassay in which serum neopterin and a known quantity of radiolabelled neopterin were incubated with a high affinity antibody to neopterin. The immune complex thus formed contains radiolabelled and unlabelled antigen. The complex was then incubated with a secondary precipitating antibody. The quantity of radioactive label in the precipitated immune complexes is inversely related to the amount of neopterin in the sample. Normal serum neopterin concentrations are $\leqslant 10 \mathrm{nmol} / \mathrm{l}$.

Serum HIV p24 antibody concentration was measured by a non-competitive sandwich assay using a recombinant protein constructed from the HIV-I p24 protein. Bound antibody was detected with antihuman IgG conjugated to fluorescein isothiocyanate. Concentrations below 20 fluorescent units $/ \mathrm{ml}$ (the cut off concentration) could not be distinguished from negative and were assigned a concentration that was half the difference between this and zero.

\section{STATISTICAL ANALYSIS}

Concentrations of laboratory markers at weeks 8-12 were defined as either the week 8 or week 12 concentration if only one was available or as the mean if both were available. Previous studies have shown that CD4+lymphocyte count and p24 antigen and $\beta_{2}$ microglobulin concentration do not change substan- tially between eight and 12 weeks after zidovudine treatment is started. ${ }^{347}$ Patients with a missing baseline or week 8-12 concentration for a particular variable were excluded from all analyses using that variable.

Proportional hazards models ${ }^{10}$ were fitted using SAS analysis. ${ }^{11}$ These models assume that the ratio of any two subjects' instantaneous risk of death (hazard rate) is constant over time. Formal tests of this assumption showed no significant evidence against it for any of the analyses. ${ }^{12}$ The regression coefficients from the models were exponentiated to produce estimated relative hazards. Baseline variables predicting prognosis were selected for a multivariate model by a stepwise search of all baseline variables with continuous variables untransformed, logarithmically transformed, and treated as categories. Raw marker concentrations at weeks 8-12, their logarithms and categorisations, and their absolute, relative, and categorical changes from baseline were each added to the best baseline model to assess their additional prognostic value. Survival curves for groups of patients were calculated by the productlimit method, ${ }^{13}$ and the significance of changes in markers between baseline and 8-12 weeks was assessed by the Wilcoxon matched pairs signed rank test. ${ }^{14}$

\section{Results}

Ninety patients ( 87 men, three women) were eligible for analysis. They were taken from the University of California, San Francisco (39 patients), Beth Israel Medical Center (20), Johns Hopkins Hospital (16), Mount Sinai Hospital (seven), Tulane University Hospital and Charity Hospital of New Orleans (five), and Memorial Sloan Kettering Cancer Center (three). At entry to the study they had a median age of 36.5 years (range 22-60) and a mean Karnofsky performance state of 90 (range 50-100); AIDS had been diagnosed in 59 patients and AIDS related complex in 31.

Baseline values for CD4+lymphocyte count were available for 79 patients, p24 antibody and neopterin concentration for 89 , and $\beta_{2}$ microglobulin and p24 antigen concentration for all 90. Baseline mean, median, and range of values for these markers are summarised in table I.

Fifty six patients died during follow up after a median 17 months (range 3-29). The remaining 34 patients were followed up for a median 25.5 months (range 10-35) and had a median Karnofsky performance state score of $72 \cdot 5$ (range $50-100$ ) when they were last seen. Nine of these patients who were lost to follow up before the end of the study had a median follow up of 16 months (range 10-23). All others had at least 24 months of follow up. Overall median survival was 24 months (21 months for patients with AIDS and

TABLE I-Baseline marker values for patients treated with zidovudine

\begin{tabular}{|c|c|c|c|c|c|c|c|c|c|}
\hline \multirow[b]{2}{*}{ Variable } & \multicolumn{3}{|c|}{ Patients with AIDS } & \multicolumn{3}{|c|}{ Patients with AIDS related complex } & \multicolumn{3}{|c|}{ Total } \\
\hline & No $(\%)$ & Median & Range & No $(\%)$ & Median & Range & No $(\%)$ & Median & Range \\
\hline CD4+lymphocyte count $\left(\times 10^{4} / 1\right)$ & & 64 & $4-740$ & & 129 & $2-384$ & & 66 & $2-740$ \\
\hline$>0 \cdot 2$ & $3(6)$ & & & $6(19)$ & & & $9(11)$ & & \\
\hline $0 \cdot 1-0 \cdot 2$ & $11(23)$ & & & $11(35)$ & & & $22(28)$ & & \\
\hline$<0 \cdot 1$ & $34(71)$ & & & $14(45)$ & & & $48(61)$ & & \\
\hline p24 Antigen (ng/l) $\dagger$ & & 232 & $76-10834$ & & 459 & $67-5284$ & & 329 & $67-10834$ \\
\hline Positive & $36(61)$ & & & $17(55)$ & & & $53(59)$ & & \\
\hline Negative & $23(39)$ & & & $14(45)$ & & & $37(41)$ & & \\
\hline p24 Antibody (fluorescent & & & & & & & & & $20-87000$ \\
\hline units $/ \mathrm{ml}) \dagger$ & & 61 & $20-87000$ & & 117 & $20-3383$ & & 81 & \\
\hline Positive & $34(59)$ & & & $22(71)$ & & & $56(63)$ & & \\
\hline Negative & $24(41)$ & & & $9(29)$ & & & $33(37)$ & & \\
\hline$\beta_{2}$ Microglobulin $(\mathrm{nmol} / \mathrm{l})$ & & $4 \cdot 9$ & $1 \cdot 8-13 \cdot 5$ & & $4 \cdot 0$ & $2 \cdot 6-6 \cdot 4$ & & $4 \cdot 4$ & $1 \cdot 8-13 \cdot 5$ \\
\hline$<254$ & $4(7)$ & & & $3(10)$ & & & $7(8)$ & & \\
\hline $254-508$ & $37(63)$ & & & $26(84)$ & & & $63(70)$ & & \\
\hline$>508$ & $18(31)$ & & & $2(6)$ & & & $20(22)$ & & \\
\hline Neopterin $(\mathrm{nmol} / \mathrm{l})$ & & 22 & $4-142$ & & 18 & $8-49$ & & 20 & $4-142$ \\
\hline$<10$ & $2(3)$ & & & $2(6)$ & & & $4(4)$ & & \\
\hline $10-15$ & $11(19)$ & & & $10(32)$ & & & $21(24)$ & & \\
\hline$>15$ & $45(78)$ & & & $19(61)$ & & & $64(72)$ & & \\
\hline
\end{tabular}

tMedian, mean, and range are calculated only for values that exceed the lower sensitivity (cut off value) of the assay 
TABLE II - V'alues for surrogate markers of HIV'activity a fter and before 8-12 weeks of zidovudine treatment in patients with AIDS or AIDS related complex

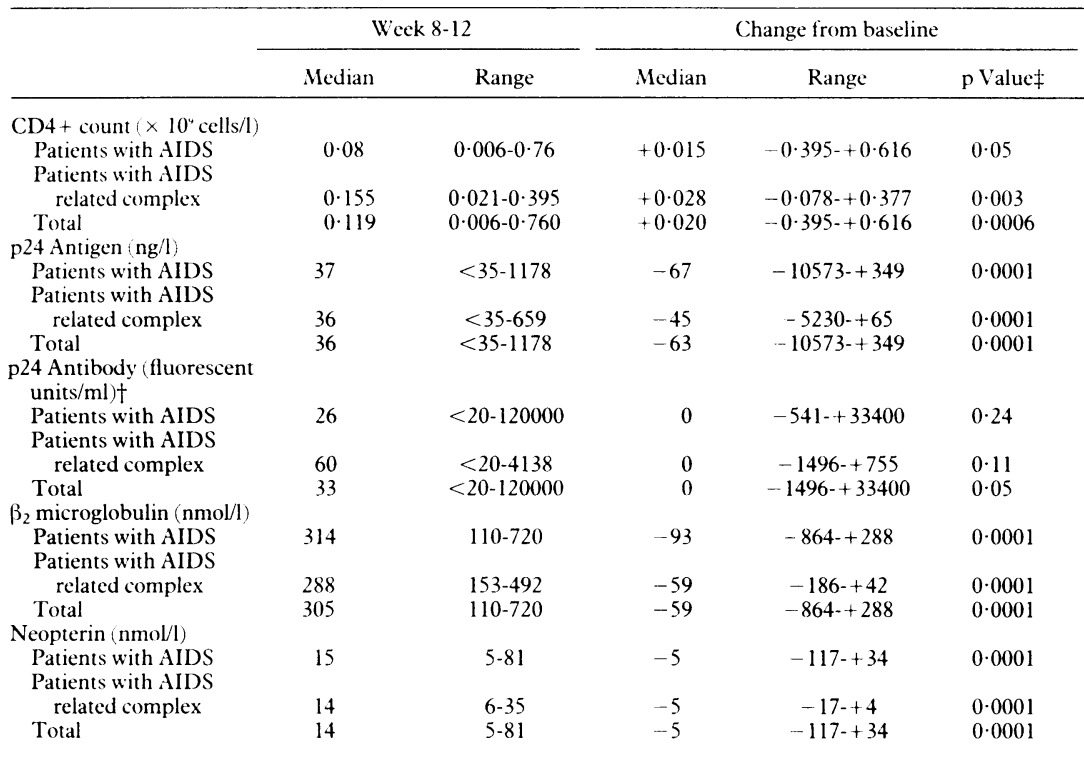

† Median, mean, and range values include measurements which are below the lower sensitivity (cut off value) of the assay. These are assigned half the cut off value of the assay.

$\ddagger$ Using the $W$ ilcoxon mixed pairs signed rank test.

TABLE III-Proportional hazards models of survival times of patients with AIDS and AIDS related complex treated with zidovudine.

\begin{tabular}{|c|c|c|c|}
\hline Variable & $\mathrm{p}$ Value & Relative hazard & $95 \%$ Confidence interval \\
\hline \multicolumn{4}{|c|}{ Baseline trivariate model } \\
\hline AIDS diagnosis & 0.002 & $3 \cdot 1$ & 1.6 to 6.5 \\
\hline Age $>45$ years & $0 \cdot 001$ & $3 \cdot 1$ & 1.6 to 5.9 \\
\hline Logarithm neopterin & $0 \cdot 001$ & $2 \cdot 1$ & $1 \cdot 3$ to $3 \cdot 4$ \\
\hline \multicolumn{4}{|c|}{ Other baseline laboratory variables (controlled for AIDS and age $>45$ ) } \\
\hline Raw neopterin $($ per $10 \mathrm{nmol} / \mathrm{l})$ & $0 \cdot 005$ & $1 \cdot 2$ & $1 \cdot 1$ to $1 \cdot 3$ \\
\hline Neopterin $>15 \mathrm{nmol} / 1$ & $0 \cdot 05$ & $2 \cdot 1$ & 1.0 to 4.4 \\
\hline $\operatorname{Raw} \beta_{2}$ microglobulin $($ per $84.75 \mathrm{nmol} / \mathrm{l})$ & 0.05 & $1 \cdot 2$ & 1.0 to 1.4 \\
\hline Logarithm $\beta_{2}$ microglobulin & $0 \cdot 13$ & $2 \cdot 0$ & 0.8 to $5 \cdot 0$ \\
\hline$\beta_{2}$ microglobulin $>381 \mathrm{nmol} / 1$ & $0 \cdot 07$ & 1.8 & 0.9 to $3 \cdot 5$ \\
\hline Raw CD $4+\operatorname{count}\left(\right.$ per $0 \cdot 1 \times 10^{\prime \prime}$ cells $\left./ \mu \mathrm{l}\right)$ & 0.66 & 0.9 & 0.7 to 1.3 \\
\hline Logarithm CD4+ count & $0 \cdot 15$ & 0.8 & $0 \cdot 6$ to $1 \cdot 1$ \\
\hline CD $4+$ count $<0 \cdot 1 \times 10^{4}$ cells $/ \mu \mathrm{l}$ & $0 \cdot 21$ & 1.5 & 0.8 to $3 \cdot 0$ \\
\hline Logarithm p24 antigen & $0 \cdot 14$ & $1 \cdot 1$ & 1.0 to 1.3 \\
\hline p24 Antigen >cut off value of assay & 0.05 & 1.7 & $1 \cdot 0$ to $3 \cdot 1$ \\
\hline Logarithm p24 antibody & $0 \cdot 20$ & $0 \cdot 9$ & $0 \cdot 8$ to $1 \cdot 1$ \\
\hline p24 Antibody $<40$ fluorescent units $/ \mathrm{ml}$ & $0 \cdot 20$ & $1 \cdot 4$ & 0.8 to $2 \cdot 5$ \\
\hline
\end{tabular}

29 months for those with AIDS related complex). Patients received zidovudine treatment for a median $80 \%$ (range $14-100 \%$ ) of the time they were followed up and received a total daily dose of at least $500 \mathrm{mg}$ for a median $69 \%$ (range $4-100$ ) of the time.

Median, mean, and range concentrations of serum p24 antigen, $\beta_{2}$ microglobulin, neopterin, p24 antibody, and CD4+lymphocyte count before treatment and after 8-12 weeks of treatment are summarised in table II. Decreases in p24 antigen, neopterin, and $\beta_{2}$ microglobulin concentrations during the first 8-12 weeks of zidovudine treatment were highly significant both in patients with AIDS $(p<0.0001)$ and in those with AIDS related complex $(p<0 \cdot 0001)$. There were significant increases in CD4+lymphocyte counts in both subgroups $(p=0.05, p=0.03)$, though a marginally significant increase in p24 antibody concentration was found only when both subgroups were combined $(\mathrm{p}=0.05)$.

\section{BASELINE VALUES PREDICTING SURVIVAL}

Using multivariate Cox proportional hazards models two baseline clinical characteristics independently predicted poor long term survival: diagnosis of AIDS ( $v$ AIDS related complex) and age over 45 years (table III). Baseline Karnofsky performance state did not add significant predictive power to these two characteristics (relative hazard $=0 \cdot 8 / 10$ points, $95 \%$ confidence interval 0.7 to $1 \cdot 0, \mathrm{p}=0 \cdot 10$ ). When controlling for AIDS $v$ AIDS related complex and age the logarithm of baseline serum neopterin concentration was an additional independent predictor of survival and was the laboratory marker with the most powerful independent predictive value for survival (table III). $\beta_{2}$ microglobulin and p24 antigen positivity each added marginal predictive power to the two clinical characteristics but were not comparable in strength with neopterin, and no other laboratory marker added independent predictive value to the model. No baseline measure significantly improved the trivariate model with AIDS, age over 45, and logarithm neopterin concentration (table III).

We divided the patients into two groups according to whether they had a good or poor baseline prognosis by multiplying the logarithm neopterin concentration and indicator variables for AIDS and age over 45 years by the corresponding coefficients from the proportional hazards model and then summing to obtain an overall weighted risk coefficient. The 39 patients with the highest coefficients constituted the poor prognosis group. For our patients this grouping was equivalent to placing all patients with two or more variables (AIDS, age over 45 , and neopterin concentration greater than $17 \mathrm{nmol} / \mathrm{l})$ in the poor prognosis group and those with only one or no variables in the good prognosis group. Figure 1 compares the survival rates of these two groups.

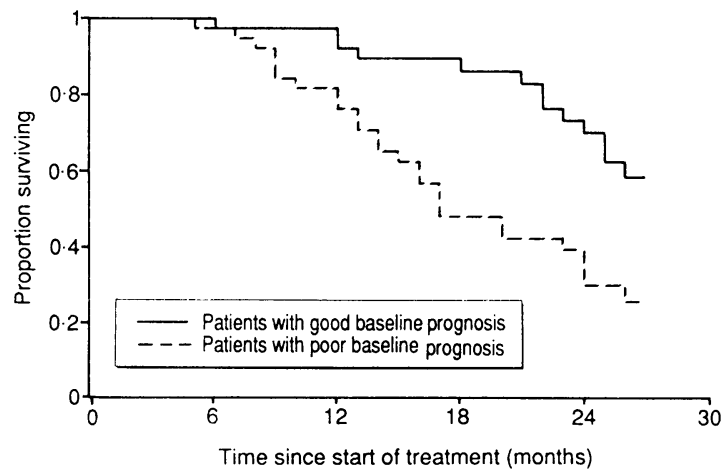

FIG 1-Survival curves for 38 patients with good baseline prognosis and 38 with poor baseline prognosis treated with zidovudine. Numbers of patients at risk at six, 12,18 , and 24 months are $38,37,28$, and 23 for the patients with good prognosis and 37, 30,17, and 13 for those with poor prognosis. (Survival curves shown only for patients for whom full marker data were available)

\section{SURROGATE MARKERS FOR SURVIVAL}

To determine if any changes in viral or immunological markers after the start of zidovudine treatment predicted survival, we analysed the effect of adding the following to the three baseline predictors: raw and logarithm absolute marker values at weeks 8-12 of treatment and changes in raw and logarithm marker values between baseline and weeks $8-12$. The analysis was limited to the 89 patients who survived for more than 12 weeks. When controlled for AIDS versus AIDS related complex diagnosis, age over 45 , and logarithm of baseline serum neopterin concentration, a low value for the logarithm of CD4+lymphocyte count at weeks 8-12 or a low CD4+ count, itself, and, to a less extent, any increase in serum $\beta_{2}$ microglobulin concentration at weeks 8-12 compared with baseline were the measurements that predicted an increased risk of death (table IV). For CD4+ count, the relative hazard was 0.7 for each increase of $0.1 \times 10^{9}$ cells $/ 1$. When controlled for AIDS or AIDS related complex, age, and baseline neopterin concentration, neither absolute values nor changes during zidovudine treatment of neopterin, p24 antigen, or p24 antibody concentrations had predictive value for outcome (table IV). 
MULTIVARIATE ANALYSIS OF SURROGATE MARKERS

As the logarithm of CD4+lymphocyte count at weeks $8-12$ seemed to be the most powerful surrogate marker correlating antiretroviral effect to survival we extended the multivariate analysis to control for this variable as well as the three independently predictive baseline characteristics (AIDS or AIDS related

TABLE IV-Proportional hazards models of survival times of patients with AIDS and AIDS related complex treated with zidovudine: additional laboratory variables reflecting zidovudine effect after 8-12 weeks of treatment (controlled for AIDS diagnosis, age $>45$, and logarithm neopterin at baseline)

\begin{tabular}{|c|c|c|c|}
\hline Variable & $\mathrm{p}$ Value & Relative hazard & $\begin{array}{l}\text { 95\% Confidence } \\
\text { interval }\end{array}$ \\
\hline $\begin{array}{l}\text { Logarithm CD4+ lymphocyte count at week 8-12 } \\
\text { Raw CD4+lymphocyte count at week 8-12 }\end{array}$ & $0 \cdot 007$ & $0 \cdot 6$ & 0.5 to 0.9 \\
\hline$\left(\right.$ per $0.1 \times 10^{4}$ cells $\left./ \mu \mathrm{l}\right)$ & $0 \cdot 04$ & $0 \cdot 7$ & 0.5 to 1.0 \\
\hline $\begin{array}{l}\text { Change in logarithm CD } 4+\text { count between baseline } \\
\text { and week } 8-12\end{array}$ & $0 \cdot 31$ & $0 \cdot 9$ & 0.6 to 1.2 \\
\hline $\begin{array}{l}\text { Change in raw CD } 4+\text { count between baseline and } \\
\text { week } 8-12\left(\text { per } 0.1 \times 10^{\circ} \text { cells } / \mu 1\right)\end{array}$ & $0 \cdot 11$ & $0 \cdot 8$ & 0.6 to $1 \cdot 1$ \\
\hline Any decrease in CD4+ count & $0 \cdot 22$ & 1.6 & 0.6 to $1 \cdot 2$ \\
\hline Logarithm $\beta_{2}$ microglobulin at week $8-12$ & $0 \cdot 50$ & 0.8 & 0.3 to 1.7 \\
\hline $\operatorname{Raw} \beta_{2}$ microglobulin at week $8-12(\operatorname{per} 84.75 \mathrm{nmol} / \mathrm{l})$ & $0 \cdot 54$ & $0 \cdot 9$ & 0.8 to $1 \cdot 2$ \\
\hline $\begin{array}{l}\text { Change in logarithm } \beta_{2} \text { microglobulin between } \\
\text { baseline and week } 8-12\end{array}$ & $0 \cdot 61$ & $0 \cdot 8$ & 0.4 to 1.8 \\
\hline $\begin{array}{l}\text { Change in raw } \beta_{2} \text { microglobulin between baseline } \\
\text { and week } 8-12\end{array}$ & $0 \cdot 50$ & $0 \cdot 9$ & $0 \cdot 8$ to $1 \cdot 1$ \\
\hline Any increase in $\beta_{2}$ microglobulin & 0.05 & $2 \cdot 1$ & 1.0 to 4.4 \\
\hline Logarithm neopterin at week $8-12$ & $0 \cdot 23$ & $1 \cdot 4$ & 0.8 to $2 \cdot 4$ \\
\hline Raw neopterin at week $8-12($ per $10 \mathrm{nmol} / 1)$ & $0 \cdot 41$ & $1 \cdot 1$ & 0.9 to 1.3 \\
\hline $\begin{array}{l}\text { Change in logarithm neopterin between baseline } \\
\text { and week } 8-12\end{array}$ & $0 \cdot 23$ & $1 \cdot 4$ & $0 \cdot 8$ to $2 \cdot 4$ \\
\hline $\begin{array}{l}\text { Change in raw neopterin between baseline } \\
\text { and week } 8-12\end{array}$ & $0 \cdot 21$ & $1 \cdot 2$ & 0.9 to 1.5 \\
\hline Any neopterin increase & 0.94 & 1.0 & 0.5 to $2 \cdot 3$ \\
\hline Logarithm p24 antigen at week $8-12$ & $0 \cdot 42$ & $1 \cdot 1$ & 0.9 to 1.4 \\
\hline $\begin{array}{l}\text { Change in logarithm p } 24 \text { antigen between baseline } \\
\text { and week 8-12 }\end{array}$ & $0 \cdot 65$ & $0 \cdot 9$ & $0 \cdot 7$ to $1 \cdot 2$ \\
\hline Any p24 antigen increase & $0 \cdot 22$ & $0 \cdot 7$ & $0 \cdot 4$ to $1 \cdot 2$ \\
\hline Logarithm p24 antibody at week $8-12$ & $0 \cdot 35$ & $0 \cdot 9$ & 0.8 to 1.1 \\
\hline $\begin{array}{l}\text { Change in logarithm p } 24 \text { antibody between baseline } \\
\text { and week } 8-12 \\
\text { Any p } 24 \text { antibody decrease }\end{array}$ & $\begin{array}{l}0 \cdot 64 \\
0 \cdot 84\end{array}$ & $\begin{array}{l}0.9 \\
0.9\end{array}$ & 0.5 to 1.5 \\
\hline Any p24 antibody decrease & $0 \cdot 84$ & 0.9 & \\
\hline
\end{tabular}
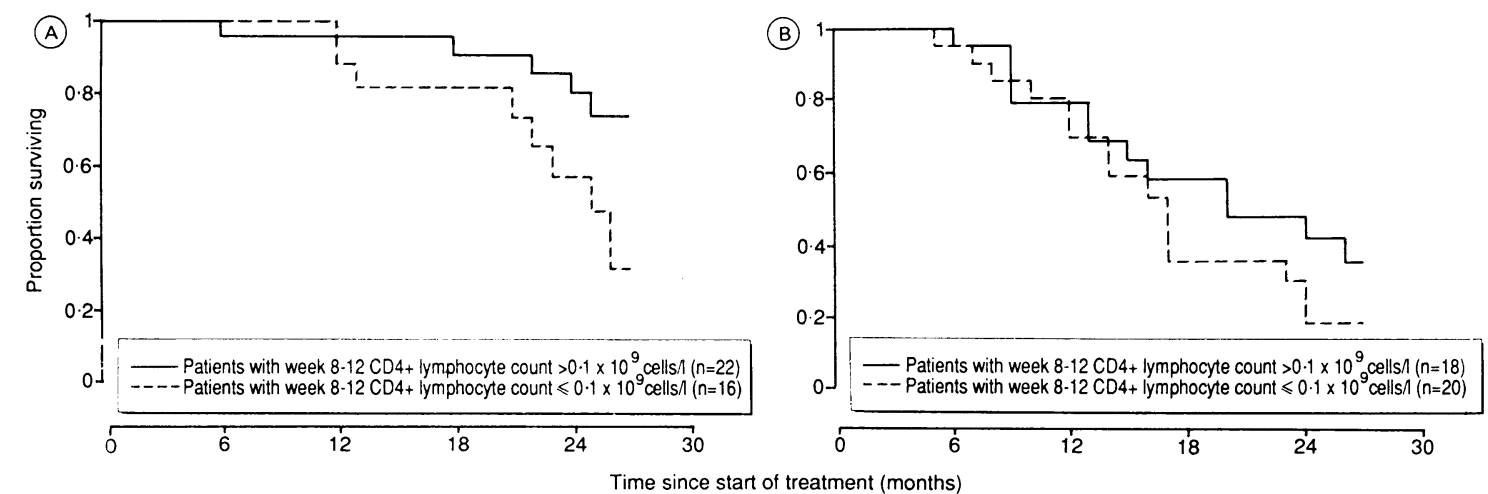

FIG 2-Survival curves for patients treated with zidovudine grouped according to baseline prognosis and CD4+lymphocyte count at week 8-12. (a) Patients with good baseline prognosis. Numbers of patients at risk at six, 12, 18, and 24 months are 22, 21, 18, and 16 for the patients with $>0 \cdot 1 \times 10^{\circ} \mathrm{CD} 4+$ lymphocytes/l and $16,16,10$, and seven for those with $\leqslant 0 \cdot 1 \times 10^{\circ} \mathrm{CD} 4+$ lymphocytes $/ l$. (b) Patients with poor baseline prognosis. Numbers of patients at risk at six, 12,18 , and 24 months are $18,15,11$, and eight for the patients with $>0 \cdot 1 \times 10^{\circ} \mathrm{CD} 4+$ lymphocytes/l and 19,15 , six, and five for those with $\leqslant 0 \cdot 1 \times 10^{\circ} \mathrm{CD} 4+$ lymphocytes/l
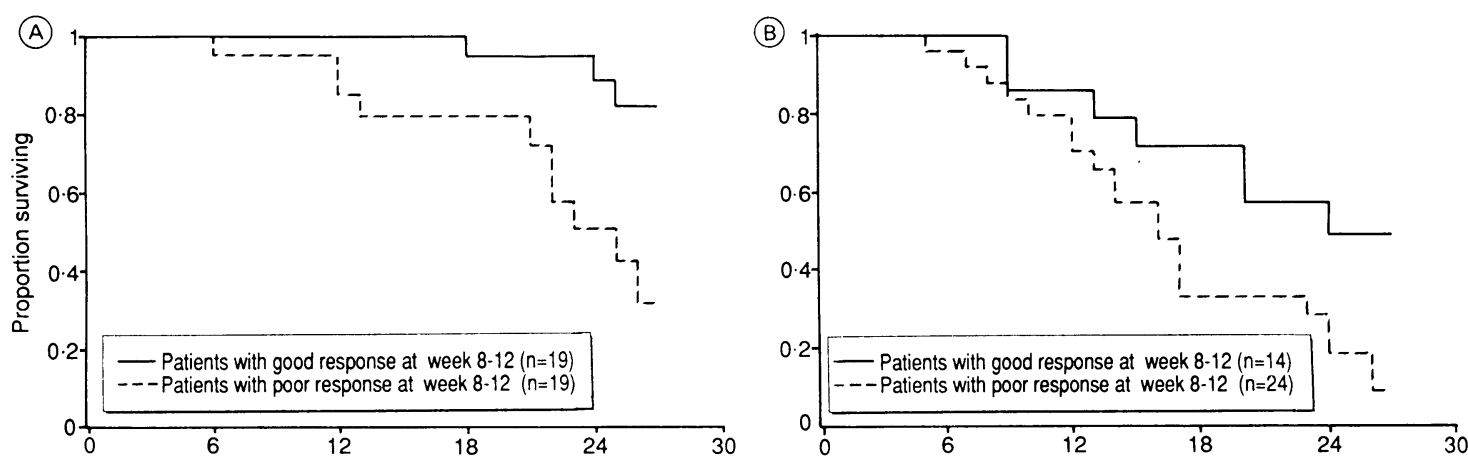

FIG 3-Survival curves for patients treated with zidovudine, grouped according to baseline prognosis and response of CD4+ lymphocyte count and $\beta_{2}$ microglobulin concentration to treatment. (a) Patients with good baseline prognosis. Numbers of patients at risk at six, 12, 18, and 24 months are $19,19,17$, and 16 for the patients with good response and 19,18,12, and seven for those with poor response. (b) Patients with poor baseline prognosis. Numbers of patients at risk at six, 12, 18, and 24 months are 14, 12, 10, and seven for the patients with good response and 23, 18, seven, and six for those with poor response complex, age over 45 , logarithm serum neopterin concentration) to evaluate any independent contribution of other surrogate markers during zidovudine tion between baseline and weeks 8-12 was the only variable that significantly improved the model (relative hazard $=2 \cdot 3,95 \%$ confidence interval $1 \cdot 0$ to $5 \cdot 5$,

We then examined the relation between the two potential surrogate markers, CD4+lymphocyte count and change in $\beta_{2}$ microglobulin concentration during groups defined by pretreatment characteristics (figs 2 and 3). Using CD4+ lymphocyte count at weeks 8-12 defined as a CD4 4 count greater a good response was (fig 2).

microglobulin concentration as well, we multiplied the week 8-12 log CD4+count and an indicator variable for decrease in $\beta_{2}$ microglobulin concentration by the corresponding coefficients from the proportional and baseline logarithm for AIDS age over 45 years, two products were then added to produce an overall weighted response coefficient, and this was then This is equivalent to defining a poor response as either less than or equal to $0.085 \times 10^{9} \mathrm{CD} 4+$ lymphocytes/ 1 at weeks $8-12$ or no decrease in $\beta_{2}$ microglobulin both). Figure 3 shows the survival rates from good and poor responders, separately for those with a good boor responders, prognosis (fig 3a) and for those with a poor one
baseline 
(fig 3b). For the good and poor responders the proportions of those in the good pretreatment prognosis category surviving at 24 months were estimated by the product-limit method to be $88 \%$ and $50 \%$ respectively (fig 3a). For good and poor responders with a poor pretreatment prognosis the proportions surviving at 24 months were estimated to be $49 \%$ and $18 \%$ respectively (fig 3b).

\section{Discussion}

The standard method of evaluating the efficacy of new drugs has been to conduct controlled, prospective trials using clinically relevant end points as the main outcome measure. In the case of HIV disease, the standard end points of death or development of new AIDS defining opportunistic infections or neoplasms can take months or years to reach. ${ }^{3+}$ Thus the development of laboratory markers which can serve as surrogate end points for quickly evaluating new antiretroviral treatment has become a high priority for clinical investigation. A symposium convened by the National Academy of Sciences Institute of Medicine in September 1989 emphasised the urgent need for defining and validating such surrogate end points for antiretroviral efficacy in patients with HIV disease.

Direct viral markers of HIV activity such as serum p24 antigen concentration are particularly appealing as surrogate end points, but problems in reproducibility have been reported, and the marker is not present in all patients. ${ }^{1617}$ Immune markers such as CD4+ lymphocyte count, serum $\beta_{2}$ microglobulin, and serum neopterin concentrations, although less directly linked to HIV replication, have the advantage of better reproducibility and can be measured in all patients. ${ }^{18} 19$

We examined the early effects of zidovudine treatment on five potential surrogate viral and immunological markers of HIV activity in a group of 90 patients with AIDS or AIDS related complex who were followed up for a median of two years or until death. These markers were those identified in epidemiological studies as being predictors of progression to AIDS in $\mathrm{HIV}$ infected homosexual men and in clinical trials as tending to revert to normal in response to zidovudine treatment ${ }^{3+671719}$ (P Crocchiolo et al, 4th international conference on AIDS, Stockholm, 1988). To control for the clinical heterogeneity of this group we first determined that diagnosis of AIDS (versus AIDS related complex), age over 45 years at entry, and the logarithm of baseline serum neopterin concentration were the pretreatment characteristics best able to predict survival. Baseline serum $\beta_{2}$ microglobulin concentration had marginal predictive power but neither baseline CD4+count, serum p24 antigen, nor antibody concentration predicted survival. Previous studies of patients with AIDS not receiving antiretroviral treatment have shown that age over 40 years predicts poor survival, ${ }^{2021}$ and immune response markers such as raised serum neopterin or $\beta_{2}$ microglobulin concentrations have been associated with poor prognosis in many epidemiological studies. ${ }^{17} 1922-24$ Baseline Karnofsky performance state, which had previously been reported to be among the most powerful baseline clinical predictors of survival in patients with AIDS treated with zidovudine and followed up for six months, ${ }^{52}$ did not add significant predictive power to our model, perhaps because our follow up was much longer or because a substantial number of our patients had not yet been diagnosed as having AIDS.

After 8-12 weeks of zidovudine treatment the most powerful surrogate marker for predicting long term survival (when controlled for pretreatment characteristics and conditional on survival over 12 weeks) was the logarithm of CD4+lymphocyte count. Raw CD4+ lymphocyte count itself was a less powerful predictor. Change in CD4+lymphocyte count during treatment, however, was not a surrogate marker for survival. Thus patients maintaining a particular CD4+lymphocyte count at 8-12 weeks (for example, CD4+ count $=$ $0 \cdot 1 \times 10^{9}$ cells $/ 1$ ) had the same prognosis as those whose count rose or fell to this level during treatment. When we examined other laboratory markers a decrease in $\beta_{2}$ microglobulin concentration between baseline and week 8-12 was the only other measure that appeared to add any additional predictive power to the model.

The CD4+lymphocyte is a target for HIV infection, and zidovudine markedly reduces HIV replication in cultured lymphocytes. ${ }^{2}$ Endogenous $\beta_{2}$ microglobulin is produced mainly by lymphocytes, and synthesis increases after mitogenic stimulation of cultured lymphocytes. ${ }^{26}$ Hence, it was predicted and observed in previous controlled studies that zidovudine's antiretroviral activity would result in increased CD4+ lymphocyte count and decreased serum $\beta_{2}$ microglobulin concentration. ${ }^{37}$ We have now found that the degree of these two salutary effects of zidovudine treatment on the immune system, early in treatment, are correlated with long term survival. Patients who had higher CD4+lymphocyte counts and whose serum $\beta_{2}$ microglobulin concentration did not increase after the first 8-12 weeks of zidovudine treatment had better long term survival. This observation suggests that both CD4+lymphocyte count and serum $\beta_{2}$ microglobulin concentration could be useful surrogate end points for trials of new antiretroviral drugs in patients with HIV disease. These results agree with epidemiological prospective studies, in which CD4+lymphocyte count and serum $\beta_{2}$ microglobulin concentration are among the most powerful predictors of progression to clinical AIDS in HIV infected homosexual men, and in which the two predictors have been shown to have independent effects. ${ }^{17} 1923$

Although serum neopterin concentration decreased significantly during zidovudine treatment (table II), perhaps as a consequence of decreased interferon $\gamma$ production from zidovudine sensitive HIV infected lymphocytes, ${ }^{27}$ this decrease did not correlate with survival when controlled for baseline predictors. Perhaps if we had assayed at a different time during treatment changes in neopterin concentration might have correlated with outcome. An alternative hypothesis is that increased serum neopterin concentration might result from direct HIV activation of chronically infected monocytes or macrophages, long lived cells in which zidovudine at plasma achievable concentrations does not effectively inhibit virus replication. This hypothesis may be tested only when drugs targeted against infected monocytes or macrophages are available. Such drugs might produce greater decreases in serum neopterin concentrations during treatment that could correlate with outcome.

Neither absolute nor relative measures of p24 antigen concentration during zidovudine treatment correlated with survival when controlled for baseline predictors. In previous studies serum p24 antigen concentration has significantly decreased during zidovudine treatment, presumably due to the drug's specific antiretroviral activity in HIV infected lymphocytes. ${ }^{6}$ Hence, we were surprised by the lack of correlation between p 24 antigen concentration during treatment and long term survival. Early in treatment, changes in p24 antigen concentration may reflect only an immediate antiretroviral effect on virus replication whereas changes in CD4+lymphocyte count and $\beta_{2}$ microglobulin concentration may reflect a more prolonged effect that zidovudine induced interruption of the HIV life cycle has on the immune system. As a surrogate end point p24 antigen concentration has the disadvantage of being detectable in only two thirds of 
patients with advanced HIV disease. ${ }^{67}$ Alternatively, $\beta_{2}$ microglobulin is measurable in all patients and was abnormally raised in $93 \%$ of patients in our study at the time that zidovudine treatment was started (table I).

Recently, quantifiable measures of viraemia in plasma have been reported to be sensitive markers of clinical HIV disease, and plasma virus titres have been reported to decrease during zidovudine treatment. The polymerase chain reaction also has been proposed as a method for directly measuring HIV in vivo (S Kwok et al, 5th international conference on AIDS, Montreal, 1989). ${ }^{28}$ Such quantifiable direct viral measures are attractive as potential end points for future trials of new antiretroviral drugs and have the advantage of being more direct measures of HIV activity than immune markers. The true sensitivity and reproducibility of these techniques, however, remain to be established, and their cost is likely greatly to exceed that of the immune markers especially serum markers such as $\beta_{2}$ microglobulin and neopterin concentration. This last disadvantage may be particularly important in future definitive trials of efficacy for new antiretroviral drugs. Because control patients will necessarily receive some active standard antiretroviral regimen such as zidovudine hundreds to thousands of patients will be required. Immune markers such as CD4+lymphocyte count, $\beta_{2}$ microglobulin and neopterin concentration are relatively inexpensive, generally highly reproducibile, and may be appropriate surrogate end points for such large scale future trials.

We thank Lawrence Peiperl, Kathryn Kocurek, Atnaf Keffelew, Nancy McManus, John Mills, Marti Nash, Shirley Hagens, Alan E Greenberg, and Jonathan Lee for help in completing this study. This work was supported partly by cooperative agreement A127663 with the AIDS Clinical Trials Group of the National Institute of Allergy and Infectious Disease, funds distributed under the recommendation of the Universitywide programme on AIDS of the state of California, and a grant from Burroughs Wellcome to the San Francisco General Hospital foundation for medicine. Measurement of $\beta_{2}$ microglobulin concentration was made possible partly by a grant from Pharmacia Diagnostics.

1 Abramowicz M (ed). Azidothymidine for AIDS. The Medical Letter 1986;28 107-9.

2 Yarchoan R, Mitsuya H, Myers CE, Broder S. Clinical pharmacology of 3'-azido-2', 3'-dideoxythymidine (zidovudine) and related dideoxynucleosides. $N$ Engl F Med 1989;321:726-38.

3 Fischl MA, Richman DD, Grieco MH, et al. The efficacy of azidothymidin (AZT) in the treatment of patients with AIDS and AIDS-related complex. NEngl f Med 1987;317:185-91.
4 Fischl MA, Richman DD, Hansen N, et al. The safety and efficacy of zidovudine (AZT) in the treatment of subjects with mildly symptomatic Lidovudine $(A Z T)$ in the treatment of subjects with mildy symptomatic
human immunodeficiency virus type 1 (HIV) infection. Ann Interm Med human immunod.

5 Creagh-Kirk T, Doi P, Andrew's E, et al. Survival experience among patients with AIDS receiving zidovudine. FAMA 1988;260:3009-15.

6 Chaisson RE, Leuther MD, Allain JP, et al. Effect of zidovudine on serum human immunodeficiency virus core antigen levels: results from a placebocontrolled trial. Arch Intern Med 1988;148:2151-3.

7 Jacobson MA, Abrams DI, Volberding PA, et al. Serum beta-2 microglobulin decreases in patients with AIDS or ARC treated with azidothymidine. F Infect Dis 1989;159:1029-36.

8 Ho DD, Moudgil T, Alam M. Quantitation of human immunodeficiency viru type 1 in the blood of infected persons. N Engl F Med 1989;321:1621-

9 Goudsmit J, de Wolf F, Paul DA, et al. Expression of human immunodeficienc virus antigen in serum and cerebrospinal fluid during acute and chronic infection. Lancet 1986;ii:177-80.

10 Cox DR, Oakes D. Analysis of survival data. London: Chapman and Hall, 1984:91-111.

11 SAS Institute. SUGI supplemental library user's guide. Version 5. Cary, North Carolina: SAS Institute, 1985

12 Harrell FE, Lee KL. Verifying assumptions of the Cox proportional hazards model. In: Proceedings of the 11th annual SAS users' group international model. In: Proceedings of the IIth annual SAS users'

13 Kanfan EL, Meier P. Nonparametric estimation from incomplete observations. fournal of The American Statistical Association 1958;53:457-81.

Journal of The American Statistical Association 1958;53:457-81.
14 Lehmann El. Nonparametrics. Oakland, California: Holden-Day, 1975: 120-31.

15 Weiss R, Mazade L, eds. Surrogate endpoints in evaluating the effectiveness of drugs against HIV infection and AIDS. Washington DC: National Academ Press, 1990.

16 Kruppenbacher JP, Mertens TH, Eggers HJ. Reproducibility of HIV antigen test. Lancet $1988 ; \mathrm{i}: 298$

17 Moss AR, Bacchetti P, Osmond D, et al. Seropositivity for HIV and the development of AIDS or AIDS related condition: three year follow up of the San Francisco General Hospital cohort. BMF 1988;296:745-50.

18 Taylor JMG, Fahey JL, Detels R, Giorgi JV. CD4 percentage, CD4 number, and CD4:CD8 ratio in HIV infection: which to choose and how to use Journal of AIDS 1989;2:114-24

19 Fahey JL, Taylor JMG, Detels R, et al. The prognostic value of cellular and serologic markers in infection with human immunodeficiency virus type 1. N Engl F Med 1990;322:166-72.

20 Rothenberg R, Woelfel M, Stoneburner R, Milberg J, Parker R, Truman B. Survival with the acquired immunodeficiency syndrome: experience with 5833 cases in New York City. N Engl f Med 1987;317:1297-302.

21 Bacchetti P, Osmond D, Chaisson RE, et al. Survival patterns of the first 500 patients with AIDS in San Francisco. J Infect Dis 1988;157:1044-7.

22 Kramer A, Wiktor SZ, Fuchs D, et al. Neopterin: a predictive marker of acquired immune deficiency syndrome in human immunodeficiency virus acquired immune deficiency syndrome in
infection. Fournal of AIDS 1989;2:291-6.

23 Anderson RE, Lang W, Shiboski S, Royce R, Jewell N, Winkelstein W. Use of beta-2 microglobulin level and CD4 lymphocyte count to predict develop-
ment of acquired immunodeficiency syndrome in persons with human ment of acquired immunodeficiency syndrome in persons with
immunodeficiency virus infection. Arch Intern Med 1990;150:73-7.

24 Goedert JJ, Kessler CM, Aledort LM, et al. A prospective study of human immunodeficiency virus type 1 infection and the development of AIDS in subjects with hemophilia. N Engl f Med 1989;321:1141-8.

25 Steinberg JP, Spear JB, Murphy RL, et al. Predictors of outcome in AIDS patients receiving zidovudine. Fournal of AIDS 1989;2:229-34.

26 Kubo RT, Grey HM. Structure and function of beta-2 microglobulin. In: Weigle WO, ed. Contemporary topics in immunobiology. New York, NY: Plenum Press: 1976;5:267-95.

27 Huber C, Batchelor JR, Fuchs D, el al. Immune response-associated production of neopterin: release from macrophages primarily under contro of interferon-gamma. $\mathcal{E}$ Exp Med 1984;160:310-6.

28 Schnittman SM, Psallidopoulous MC, Lane HC, et al. The reservoir for HIV-1 in human peripheral blood is a $\mathrm{T}$ cell that maintains expression of $\mathrm{CD} 4$ Science 1989;245a:305-8.

(Accepted l November 1990)
The proposals which were made by Mr. Ernest Hart at the Liverpoo meeting of the British Medical Association, in the Public Health Section, for the education, examination, and registration of plumbers, and which were subsequently taken up by the National Health Society, and repeated by Mr. Hart in a paper which he read at the Congress of Plumbers at the International Health Exhibition, London, in 1888, has had a more far-reaching and practical effect than often falls to the lot of proposals so largely affecting public health on the one hand, and trade prejudices on the other. Mr. W. R. E. Coles, a member of the Council of the National Health Society, and who gave valuable assistance to that Society in arranging the first course of lectures and examinations which were given on its behalf at the Society of Arts, subsequently persuaded Mr. Shaw, the Masters of the Plumbers' Company, and the Company itself, to take up the good work. The Plumbers' Company, with Mr. Coles as clerk, has carried on a most active and effective propaganda. There are now centres of education and examination throughout Great Britain, and at the quarterly meeting of the Court of the Company of Plumbers, held at Guildhall this week, Sir Philip
Magnus brought forward a report showing that 1,550 apprentices and journeymen plumbers are now attending plumbing classes in London and the provinces, and that at seven examinations held in the last session, the average number of passes was 44 per cent. of the total number of candidates. The President of the Local Government Board has set the seal of his official approval upon the movement, and many of the leading municipalities now require that persons engaged in plumbing work on their behalf shall hold a certificate of registration of the Plumbers' Company, implying efficiency. The time must now surely be near at hand when the further step may be taken to complete the scheme as originally laid down by Mr. Ernest Hart, to give the sanction of an Act of Parliament to the register, and to give the required protection to the public by protecting the title of registered plumber, so that none others shall assume it than those who have been duly examined and certified. Meantime it is highly satisfactory to see that public opinion has been sufficiently energetic, and the trade sufficiently enlightened, to lead to so large an amount of voluntary registration. (British Medical fournal 1891;i:31) 